\title{
Predictors of antibiotics co-prescription with antimalarials for patients presenting with fever in rural Tanzania
}

\author{
Mustafa Njozi ${ }^{1,2^{*}}$, Mbaraka Amuri ${ }^{2,3}$, Majige Selemani ${ }^{1,2}$, Irene Masanja ${ }^{1,2}$, Brown Kigahe ${ }^{1,2}$, Rashid Khatib ${ }^{1,2}$,
} Dan Kajungư ${ }^{2}$, Salim Abdula ${ }^{1}$ and Alexander N Dodoo ${ }^{2}$

\begin{abstract}
Background: Successful implementation of malaria treatment policy depends on the prescription practices for patients with malaria. This paper describes prescription patterns and assesses factors associated with co-prescription of antibiotics and artemether-lumefantrine (AL) for patients presenting with fever in rural Tanzania.

Method: From June 2009 to September 2011, a cohort event monitoring program was conducted among all patients treated at 8 selected health facilities in Ifakara and Rufiji Health and Demographic Surveillance System (HDSS). It included all patients presenting with fever and prescribed with AL. Logistic regression was used to model the predictors on the outcome variable which is co-prescription of AL and antibiotics on a single clinical visit.

Results: A cohort of 11,648 was recruited and followed up with 92\% presenting with fever. Presumptive treatment was used in 56\% of patients treated with AL. On average 2.4 (1 - 7) drugs was prescribed per encounter, indicating co-prescription of AL with other drugs. Children under five had higher odds of AL and antibiotics co-prescription $(\mathrm{OR}=0.63,95 \% \mathrm{Cl}: 0.46-0.85)$ than those aged more than five years. Patients testing negative had higher odds $(\mathrm{OR}=2.22,95 \% \mathrm{Cl}: 1.65-2.97)$ of $\mathrm{AL}$ and antibiotics co-prescription. Patients receiving treatment from dispensaries had higher odds (OR $=1.45,95 \% \mathrm{Cl}: 0.84-2.30)$ of $\mathrm{AL}$ and antibiotics co-prescription than those served in health centres even though the deference was not statistically significant.

Conclusion: Regardless the fact that Malaria is declining but due to lack of laboratories and mRDT in most health facilities in the rural areas, clinicians are still treating malaria presumptively. This leads them to prescribe more drugs to treat all possibilities.
\end{abstract}

Keywords: Cohort event monitoring, Antibiotics, Co-prescription, Artemether-lumefantrine, Tanzania

\section{Background}

Malaria remains a public health problem in Africa. It is estimated to claim about 1 million deaths and over 400 million malaria cases worldwide each year, with $90 \%$ of these deaths occurring in sub Saharan Africa [1]. In Tanzania malaria has been reported as the leading cause of death and account for $40 \%$ of all outpatient attendances in health facilities [2]. Assessment of clinical symptoms is the common method of diagnosing patient's conditions in

\footnotetext{
* Correspondence: mnjozi@ihi.or.tz

'Ifakara Health Institute, P.O. Box 78373, Dar es Salaam, Tanzania

${ }^{2}$ INDEPTH Network Effectiveness and Safety Studies of Antimalarial in Africa (INESS), Accra, Ghana

Full list of author information is available at the end of the article
}

the country, with most cases of fever being presumed to be malaria. Few health facilities are equipped with basic laboratory services or use rapid diagnostic test to provide confirmatory diagnoses of malaria; that has resulted into misdiagnosis or over diagnosis of malaria. A study conducted in Muhimbili National hospital showed $87 \%$ of patients who received antimalarial treatment with a diagnosis of severe malaria did not have detectable parasitemia, resulting in over-treatment of malaria and neglecting other potentially life threatening conditions [2].

Fever has been used as a major clinical symptom for malaria [3], Now reports show that malaria has been declining [4], while fever remains a major complaint in many outpatients clinical settings [5]. This high prevalence

\section{Biomed Central}

(c) 2013 Njozi et al.; licensee BioMed Central Ltd. This is an open access article distributed under the terms of the Creative Commons Attribution License (http://creativecommons.org/licenses/by/2.0), which permits unrestricted use, distribution, and reproduction in any medium, provided the original work is properly cited. 
of fever may still be presumed as malaria, hence a need to strengthen confirmation of malaria in order to target use of antimalarial drugs to confirmed cases only. The Tanzania National Guideline for diagnosis and treatment of malaria states that, "a careful assessment of a patient with suspected malaria is essential in order to differentiate between uncomplicated and severe disease. Eventually, laboratory investigations are done to complement clinical diagnosis. In health care facilities without laboratory services, diagnosis is based only on signs and symptoms" [6]. Malaria treatment in Tanzania is mainly based on clinical judgment in the majority of health facilities, especially lower level facilities. Most of the health facilities lack laboratory diagnostic capacity for malaria and hence most of the reported malaria cases are clinically diagnosed. According to NMCP, up to early $2009,83 \%$ of health facilities in Tanzania had no laboratory diagnostic capacity for malaria. In addition, there is a problem of inaccurate malaria microscopic diagnosis and hence misdiagnosis of patients and over use of ACT [7].

Microscopic examination of Giemsa-stained blood films remains a cornerstone of malaria diagnosis throughout Tanzania, but is only available at hospitals and some health centers. Historically, more than 5,000 of the lowest-level facilities (dispensaries and some health centers) had no laboratory diagnostic capacity, leaving health care workers at more than $90 \%$ of facilities to diagnose malaria on the basis of clinical signs and symptoms alone. According to the recent WHO guidelines, all suspected malaria cases should be parasitological confirmed prior to treatment, including children under five. NMCP's policy has changed from presumptive treatment to confirmatory parasitological diagnosis. The NMCP objective is to increase the percentage of laboratory-confirmed malaria cases in public health facilities from a baseline of $20 \%$ to $80 \%$. It is clear from numerous assessments that the quality of malaria microscopy is very poor at almost all levels of the health system. Phased rollout of RDTs began in April 2009, starting in areas of low/moderate transmission and expanded to areas of stable/high transmission. Currently, laboratory confirmation is happening in only $20 \%$ of the suspected cases and there is no system for laboratory quality assurance and quality control [8-11]. Over-diagnosis of malaria can lead to inappropriate management of other causes of fever, unnecessarily usage of antimalarials, increasing the burden of malaria treatment cost, drug resistance and unsafe treatment, or prolongation of illness and death [12-15]. Antibiotic resistance is increasingly becoming a public health problem [13]. Improvement in antibiotics prescription will reduce chances of bacterial resistance and minimize hospital costs. In hospitals, currently the costs for antibiotics accounts for more than $30 \%$ of hospital budgets, and about one third to a half of all hospitalized patients receive an antibiotic [14]. It is necessary, therefore, to define and assess the prescription patterns in order to address the problem of irrational prescribing habits, and understand types of drugs commonly co-prescribed with antimalarials $[15,16]$. The World Health Organization (WHO) discourages the use of large number of drugs per encounter and irrational co-prescription of drugs with Artemisinin based Combination Therapy (ACT) [9]. The assessment of drug utilisation is important for both clinical and economic reasons.

Several factors influences prescribing behaviour of clinicians, therefore, to improve prescription behaviour, it is necessary to understand predictors of those behaviours $[17,18]$. This paper highlights the prescription patterns and assesses the predictors of antibiotics co-prescription with artemether-lumefantrine (AL), the first line recommended antimalarial drug in Tanzania. The study was conducted within 8 government health facilities found in two Health and Demographic Surveillance Systems sites that presented with fever or history of fever and treated with AL.

\section{Methods}

The INDEPTH Effectiveness and Safety Studies of Antimalarial Drugs in Africa (INESS) is an exciting new platform that aims to enable African researchers to carry out large Phase IV trials [19]. INDEPTH Network Effectiveness and Safety Studies of Antimalarial Drugs in Africa platform (INESS) operates in two HDSSs in Rufiji District, Coast Region, and in Kilombero and Ulanga Districts, around the town of Ifakara, Morogoro Region, Tanzania. More explanations about the INESS platform is further explained by Masanja [20].

\section{Study area}

The study was conducted in 8 selected health facilities located in the Rufiji and Ifakara HDSS areas from May 2010 to December 2011. The Ifakara HDSS, situated $320 \mathrm{~km}$ south- west of Dar es Salaam, has been in operation since 1996. It covers part of Kilombero and Ulanga districts with a total population of 99,000 people, served by 14 health facilities [21]. Out of these 14 health facilities in Kilombero \& Ulanga districts only two health centers have capacity of diagnosing malaria by using microscopy, the remained facilities does not have that capacity. They are dispensaries and do not have microscopy neither trained laboratory technicians. The Rufiji HDSS is situated approximately $100 \mathrm{~km}$ south of Dar es Salaam and has been operational since 1998. It contains a population of approximately 85,000 people served by a total of 16 health facilities [22]. In Rufiji only 2 health centers and one dispensary can diagnose malaria by using microscopy. 13 health facilities do not have microscopy. 


\section{Study design}

The study design was a cohort event monitoring which was observational, longitudinal and prospective. All patients prescribed AL from the 8 selected health facilities within HDSS area were recruited. Patients were asked to come to the health facility on day 3 and day 7 for clinical evaluation and assessing their prognosis including if they have experienced any of the side effects. They could come at any day as well when they experienced any adverse event or if they have any doubts. If patients did not come at the health facility on scheduled days, they were immediately followed up on the following day at their respective households by a trained field worker, and for some patients follow ups were conducted by using phones. Phone was only used for those with mobile phones and did not turn to the health facility on scheduled days. Patients were declared lost to follow up if three attempts have been made to trace him/her at his/her households and five times by using mobile phone. Information on demographic, complaining symptoms, laboratory investigations, past medical history, past medical history, medication used and all events were recorded at recruitment and during follow ups.

\section{Study population}

All patients attended 8 selected health facilities in Ifakara and Rufiji HDSS areas that were prescribed with artemether-lumefantrine for malaria treatment regardless of their demographic characteristics.

\section{Ethical clearance}

The INESS platform and its modules passed through and were reviewed and approved by the Tanzanian National Institutes of Medical Research and IHI's Ethical Review Boards with reference number IHI/IRB/No.A67-2009.

\section{Data collection}

At recruitment and after obtaining the informed consent for participation in the study, data collection was done using a standardized questionnaire developed in English and translated into Kiswahili. Iinformation on demographic, complaining symptoms, laboratory investigations, past medical history, present medical history, medication used, history of drug reactions and all events were collected. A trained clinician interviewed patients as they come for treatment and once they were prescribed with antimalarial a clinician filled in a clinical questionnaire. Follow up information was collected by trained field workers using a standardized questionnaire on day 3 and 7.

\section{Data management and analysis}

All questionnaires used to collect information at recruitment and at follow up were taken for manual editing, validation and data entry which was done using the Epidata 3.1 [23]. Data entry was done by Ifakara Data management unit and double entry was done to minimize data entry errors. Quality of data was done by re-interviewing the patients by the field supervisor. Data cleaning and analysis was done using Stata 11 [24]. Descriptive statistics was used in reporting the major results and findings on the prescription patterns and estimation of drugs per encounter. Logistic regression was used in the assessment of predictors of antibiotics co-prescriptions. Clustering was done for health facility, assuming that individuals attending the same facility are more homogeneous. Statistical significance was based on the p-value being less than 0.05 .

\section{Results}

\section{Demographic and clinical information}

A total of 11,648 patients who were prescribed with $\mathrm{AL}$ were recruited from eight government health facilities in Ifakara HDSS and Rufiji HDSS. More than half (55\%) were female, median age was 6.4 years (Inter Quartile Range: 2 - 19) and a quarter of the patients had used medicine before getting to the health facility (see Table 1). A total of 5076 patients were tested for malaria, of them 3,953 were BS tested and 1,410 were malaria rapid diagnostic test (mRDT) tested with some had both. About $80 \%$ of those tested with Microscope were found positive with $67 \%$ of those tested with mRDT were found positive while others were treated based on their presenting clinical symptoms. See Figure 1.

On average each patient presented 2.5 symptoms/ events at recruitment. About $92 \%$ of patients presented fever as a symptom at enrolment with other common symptoms being cough, vomiting, joint pain, abdominal pain and body weakness. See Figure 2 .

All patients included in the cohort took $\mathrm{AL}$, and the average number of drugs prescribed was 2.4 drugs per patient on a single clinical visit with some receiving as many as seven drugs. Common drugs co-prescribed with AL were a class of analgesics with $51 \%$ of patients and

\begin{tabular}{|c|c|}
\hline Variables & Total $(\mathrm{N}=11648)$ \\
\hline Age, median (Inter quartile range) & $6.4(2-19)$ \\
\hline Under fives, n (\%) & $5,005(43)$ \\
\hline Female, n (\%) & $6,361(54.6)$ \\
\hline Positive malaria n, (\%) & $4,013(34.5)$ \\
\hline Temperature, mean \pm SD & $37.7 \pm 0.6^{\circ} \mathrm{C}$ \\
\hline Taken medicine before going to health facility, $\mathrm{n}(\%)$ & $2,900(25)$ \\
\hline Average number of drugs prescribed, mean \pm SD & $2.4 \pm 0.8$ \\
\hline Proportion co-prescribed AL with antibiotics, n (\%) & $2,265(19.5)$ \\
\hline
\end{tabular}




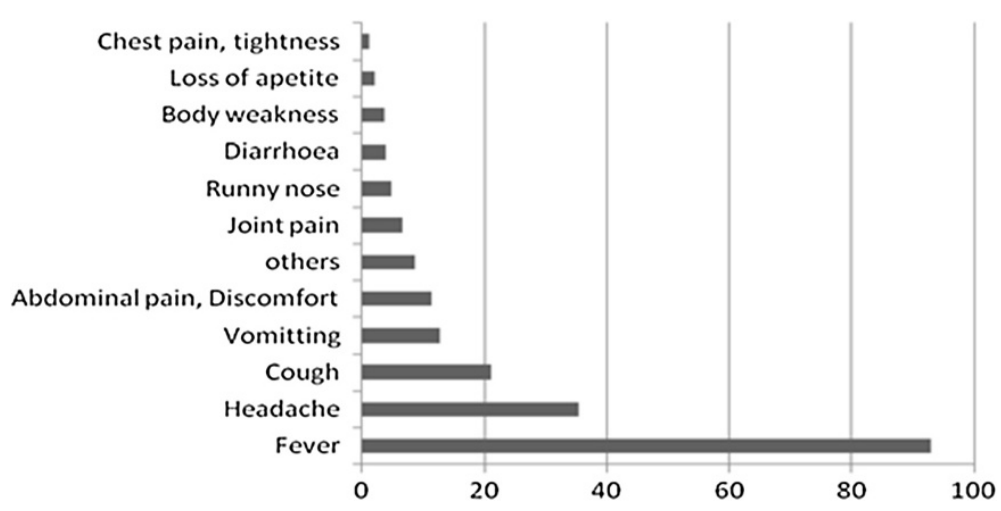

Figure 1 Presentation of diagnosis and drug prescriptions.

antibiotics were co-prescribed with AL in $20 \%$ of encounters. Other classes of drugs were co-prescribed with $\mathrm{AL}$ in less than $5 \%$ of the patients.

\section{Analysis of AL and antibiotics co-prescription}

From the univariate and multivariate analysis children aged five years and more had 0.37 lesser odds to have been co-prescribed with antibiotics as compared to older patients. Patients testing negative had higher odds of 2.12 being prescribed with AL and antibiotics as than those testing positive with malaria. There was no significant difference between not tested patients and those tested positive regarding antibiotics co-prescription. Patients diagnosed and treated at dispensaries were 1.45 higher odds to be co-prescribed with AL and antibiotics, but the difference was not significant. Gender of patients, temperature range and season of diagnosis had no influence on antibiotics co-prescription. More information on univariate and multivariate analysis results on Table 2.

\section{Discussion}

Presumptive treatment is still practiced in rural areas of Tanzania, as evident in this study where $56 \%$ of patients

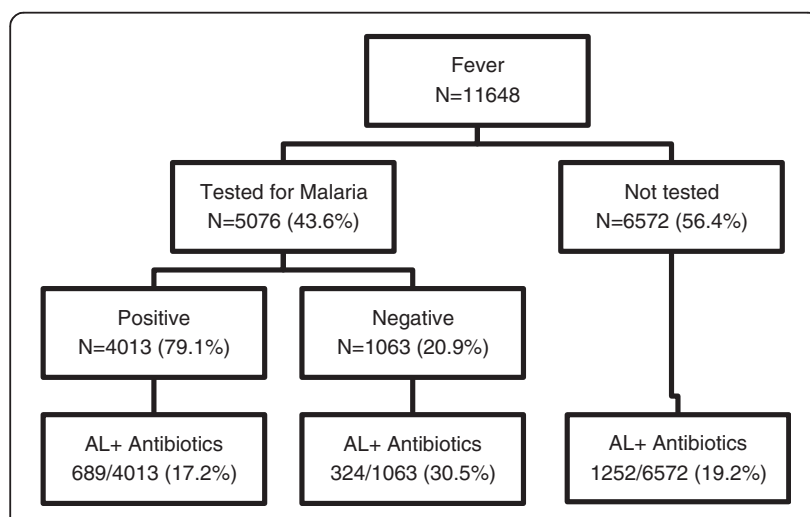

Figure 2 Proportion of common presenting symptoms. attending to government health facilities were treated with AL without parasitological confirmation. This might be due to the WHO's integrated management of childhood illness (IMCI) strategy [16]. The IMCI strategy, allows children under five years to be presumptively treated on malaria [11]. Regardless of the cost effectiveness of IMCI as explained in [25], there is a need to revise strategies for malaria treatment for children under five for improved malaria treatment outcomes and observation of other fever caused diseases. As Okebe and colleagues and Winskill et al. [26,27] suggested, children aged 5-15 have higher odds of having malaria than those under five, and this might be due to more focus on under five and causes disease burden to shift to higher age. The Tanzanian National Guidelines for diagnosis and treatment of malaria (2006) stress the use of parasitological confirmation to supplement on clinical symptoms of malaria, and allows for presumptive treatment only when facilities have no laboratory or malaria rapid diagnostic test [6].

Findings from this study shows that presumptive treatment was done for all age groups; under five and those above 5 years. Similar results of presumptive treatment for malaria patients above 5 years was fund in study done in Kenya [16]. Presumptive treatment is commonly due to lack of laboratory expertise and stock-out of mRDT. The practice is commonly done in high transmission areas like the study area [28]. This study shows $20 \%$ of patients who were treated with AL were negative, this might be due to poor training of laboratory technicians and poor slides management which leads to mistrust of results and hence clinicians dispensing $\mathrm{AL}$ basing on clinical symptoms [27]. Also reported that in some cases clinicians tends to use "mind lines" instead of guidelines when it comes to malaria treatment [29].

The mean number of drugs prescribed was 2.4 drugs per patient per encounter, which is above the $\mathrm{WHO}$ guidelines on rational use of drugs with reference values of (1.6-1.8) drugs per encounter [30]. Since all patients received AL then there was a mean of 1.4 drugs co-prescribed with AL 
Table 2 Univariate and multivariate predictors for AL co-prescribed with antibiotics

\begin{tabular}{|c|c|c|c|c|c|c|}
\hline \multirow{2}{*}{ Variable } & \multicolumn{3}{|c|}{ Univariate } & \multicolumn{3}{|c|}{ Multivariate } \\
\hline & Odds ratio & $95 \% \mathrm{Cl}$ & $P$ - value & Odds ratio & $95 \% \mathrm{Cl}$ & $P$ - value \\
\hline \multicolumn{7}{|l|}{ Age group } \\
\hline$<5$ years & Referent & & & & & \\
\hline $5+$ years & 0.63 & $0.47-0.84$ & 0.007 & 0.63 & $0.46-0.85$ & 0.009 \\
\hline \multicolumn{7}{|l|}{ Sex } \\
\hline Male & Referent & & & & & \\
\hline Female & 1.02 & $0.91-1.145$ & 0.674 & 1.09 & $0.98-1.20$ & 0.087 \\
\hline \multicolumn{7}{|l|}{ Temperature range } \\
\hline$<38.5^{\circ} \mathrm{C}$ & Referent & & & & & \\
\hline$\geq 38.5^{\circ} \mathrm{C}$ & 0.91 & $0.71-1.16$ & 0.381 & 0.85 & $0.64-1.12$ & 0.204 \\
\hline \multicolumn{7}{|l|}{ Season } \\
\hline Low transmission & Referent & & & & & \\
\hline High transmission & 1.16 & $0.72-1.87$ & 0.49 & 1.20 & $0.71-0.05$ & 0.441 \\
\hline \multicolumn{7}{|l|}{ Facility type } \\
\hline Health centre & Referent & & & & & \\
\hline Dispensary & 1.45 & $0.84-2.50$ & 0.156 & 1.39 & $0.84-2.30$ & 0.164 \\
\hline \multicolumn{7}{|l|}{ Malaria test results } \\
\hline Positive & Referent & & & & & \\
\hline Negative & 2.12 & $1.34-3.34$ & 0.006 & 2.21 & $1.65-2.97$ & 0.001 \\
\hline Not tested & 1.14 & $0.82-1.57$ & 0.383 & 1.03 & $0.69-1.54$ & 0.859 \\
\hline
\end{tabular}

observed in rural settings of Tanzania. The study had more children, and number of drugs per encounter seems lower as compared to 3.2 per encounter reported for children in Uganda [31]. Patient receiving the least number of drugs were the one who received AL alone and maximum number of drugs prescribed was 7 drugs per encounter. The number of drugs prescribed was relatively high as compared to 2.1 per person per encounter reported in previous study in Kilombero District (an area included in this study) [32].

Analgesics were commonly prescribed class of drugs as more than $50 \%$ of patients prescribed AL were coprescribed it with Analgesics. This is a common practice to clinicians and reported in other countries such as Sudan [33] and Yemen [34]. History of fever or presenting fever suggested the use of these Analgesics [35], even though the mean temperature did not suggest that as per WHO guidelines [12]. There is a good reason for prescribing analgesics with AL for patients presenting with fever, as they might need medicines to manage fever while continuing with antimalarial treatment.

The study indicates that antibiotics were co-prescribed for $20 \%$ of encounters which is less compared to $30.8 \%$ observed in Ghana [36]. Antibiotics are associated with some adverse reactions [36] and hence need to be used with great care to reduce those reactions. Other classes of drugs were co-prescribed with AL but in lower rates of less that $5 \%$ includes micronutrients supplements, antihelminths, antihistamines and antipsychotics.

Furthermore this study assessed the predictors of antibiotics co-prescription. Predictors found to be associated with the risk of being co-prescribed of other drugs with AL were age group and type of diagnosis (positive, negative and not tested). Children aged less than five years were more likely to be co-prescribed with antibiotics than those aged 5 years and more (Table 2). Similar findings were reported by Torvi et al. in [17]. This might be due to paediatrics being in high risk to suffer from recurrent infections of other systems such as the respiratory tract and gastrointestinal system as seen from Figure 1 that cough was a major symptom after fever and headache [37].

Patients with fever who had negative results on malaria, due to lack of laboratory services, clinicians tend to deal with all possibilities by giving antimalarial if fever was due to malaria and antibiotics if fever was caused by bacterial infection or analgesics for fever itself. A similar observation was done in Zanzibar as those with clinical diagnosis were more likely to be co-prescribed with antibiotics as compared to those with malaria rapid diagnosis tests (mRDT). Those who were not tested were presumptively treated and IMCI guidelines were used for children under five years [38]. For patients positive tested with malaria co prescription was given when deemed necessary as clinicians were almost certain of patient's problem. For 
those not tested, co prescription was done basing on clinical symptoms and clinicians used their knowledge at best to assess the need for the co-prescription [38].

\section{Conclusion}

Fever is still the main complain regardless malaria decline. Presumptive treatment is still practised. When a child is having fever and tested malaria negative clinicians tends to give more drugs including atimalarial to cure for all possibilities.

\section{Recommendations}

More training and supervision of clinicians' prescription pattern especially to children to avoid concomitant use of antibiotics.

Authorities should make sure that facilities are equipped with $\mathrm{mRDT}$ or laboratory for better malaria diagnosis and minimise the un-necessary prescription of antibiotics.

\section{Limitations}

Study was conducted for outpatients who were treated with artemether-lumefatrine and can never be generalized for in-patients treated with any antimalarial drug or outpatients not treated with artemether-lumefatrine. The study was non-interventional and did not assess whether prescription was appropriate for reported symptom and according to diagnosis.

\section{Competing interests}

The authors declare that they have no competing interests.

\section{Authors' contributions}

MN wrote the first draft, MN, MS and DK data analysis and reviewed manuscript, MA, RK, and IM reviewed the manuscript, AD and SA supervised the writing and contributed to the discussion. All authors read and approved the final manuscript.

\section{Acknowledgements}

The authors thank the Rufiji and Ifakara Health and Demographic Surveillance System community, the INESS Tanzania team, and all who participated in one way or another the study. The cooperation of patients from 8 selected health facilities is highly appreciated. Special thanks to the INDEPTH secretariat for their invaluable support. Thanks to Masoud Mahundi for the language editing. The study was financed by Bill and Melinda Gates foundation.

\section{Author details}

${ }^{1}$ Ifakara Health Institute, P.O. Box 78373, Dar es Salaam, Tanzania. ${ }^{2}$ INDEPTH Network Effectiveness and Safety Studies of Antimalarial in Africa (INESS), Accra, Ghana. ${ }^{3}$ Jhpiego, P.O Box 9170, Dar es Salaam, Tanzania.

Received: 30 January 2013 Accepted: 20 November 2013 Published: 27 November 2013

\section{References}

1. Mmbando BP, Vestergaard LS, Kitua AY, Lemnge MM, Theander TG, Lusingu JP a: A progressive declining in the burden of malaria in north-eastern Tanzania. Malar J 2010, 9:216. Available from: http://www.biomedcentral.com/ content/pdf/1475-2875-9-216.pdf.

2. Ahsan B, Beiranvand S, Abdulmaleki N, Mohamadi H, Kalantar E: A surveillance study of antimicrobial susceptibility in 11 hospitals in Kurdistan Province. Afr J Microbiol Res 2011, 5(20):3157-3161.

3. Abuaku BK, Koram K, Binka FN: Antimalarial prescribing practices: a challenge to malaria control in Ghana. Med Princ Pract: international journal of the Kuwait University, Health Science Centre 2005, 14(5):332-337. Available from: http://www.karger.com/Article/PDF/86931.

4. Mboera LEG, Makundi E, Kitua AY: Uncertainty in malaria control in Tanzania: crossroads and challenges for future interventions. Am J Trop Med Hyg 2007, 77(6 Suppl):112-118. Available from: http://www.ncbi.nlm. nih.gov/books/NBK1714/pdf/pg112.pdf.

5. Ogungbamigbe TO, Ogunro PS, Elemile PO, Egbewale BE, Olowu OA, Abiodun OO: Prescription patterns of antimalarial drugs among medical practitioners in osogbo metropolis. Trop Med and Health 2005, 33(4):201-208.

6. National Malaria Control Programme (NMCP) [Tanzania]: National Guidelines for Diagnosis and Treatment of Malaria. Dar es Salaam, Tanzania: National Malaria Control Programme; 2006.

7. National Malaria Control Programe (NMCP) [Tanania]: Tanzania Malaria Programe Review 2010 Programe review Proposal. Dar es Salaam: National Malaria Control Programme; 2010.

8. McMorrow ML, Masanja MI, Kahigwa E, Abdulla SMK, Kachur SP: Quality assurance of rapid diagnostic tests for malaria in routine patient care in rural Tanzania. Am J Trop Med Hyg 2010, 82(1):151-155. Available from: http://www.ncbi.nlm.nih.gov/pmc/articles/PMC2803527/pdf/tropmed-82-151. pdf.

9. Mcmorrow ML, Masanja MI, Abdulla SMK, Kahigwa E, Kachur SP: Challenges in routine implementation and quality control of rapid diagnostic tests for malaria - Rufiji District, Tanzania. Am Soc Trop Med Hyg 2008, 79(3):385-390.

10. Masanja IM, de Bethune $X$, Jacobs J: Implementing ideal health policy in a fragile health system: the example of expanding the use of malaria rapid diagnostic tests in mainland Tanzania. Malaria J 2011, 10(1):322. Available from: http://www.biomedcentral.com/content/pdf/1475-2875-10-322.pdf.

11. Masanja MI, McMorrow M, Kahigwa E, Kachur SP, McElroy PD: Health workers' use of malaria rapid diagnostic tests (RDTs) to guide clinical decision making in rural dispensaries, Tanzania. Am J Trop Med Hyg 2010, 83(6):1238-1241. Available from: http://www.ncbi.nlm.nih.gov/pmc/articles/ PMC2990037/pdf/tropmed-83-1238.pdf.

12. Reyburn H: New WHO guidelines for the treatment of malaria. BMJ 2010, 340:c2637. Available from: http://www.bmj.com/content/340/bmj.c2637.

13. Van Bijnen EME, den Heijer CDJ, Paget WJ, Stobberingh EE, Verheij R, Bruggeman C, et al: The appropriateness of prescribing antibiotics in the community in Europe: study design. BMC Infect Dis 2011, 11(1):293. Available from: http://www.biomedcentral.com/1471-2334/11/293/.

14. Riaz H, Malik F, Raza A, Hameed A, Ahmed S, Shah PA, et al: Assessment of antibiotic prescribing behavior of consultants of different localities of Pakistan. Afr J Pharm Pharmacol 2011, 5(May):596-601.

15. Chandler CIR, Chonya S, Boniface G, Juma K, Reyburn H, Whitty CJM: The importance of context in malaria diagnosis and treatment decisions - a quantitative analysis of observed clinical encounters in Tanzania. Trop Med Int Health 2008, 13(9):1131-1142.

16. Zurovac D, Njogu J, Akhwale W, Hamer DH, Larson B, Snow RW: Effects of revised diagnostic recommendations on malaria treatment practices across age groups in Kenya. Trop Med Int Health: TM \& IH 2008, 13(6):784-787.

17. Torvi JR, Dambal S: Drug prescription pattern in paediatric out patient clinic in a tertiary hospital. Pediatr Res 2011, 15(2):77-80.

18. Badar VA, Navale SB: Study of prescribing pattern of antimicrobial agents in medicine intensive care unit of a teaching hospital in. 2012, 60(APrII):20-23.

19. INDEPTH: INDEPTH Network. Available from: http://www.indepth-network.org

20. Masanja I, Selemani M, Amuri B, Kajungu D, Khatib R, Kachur P, et al: Increased use of malaria rapid diagnostic tests improves targeting of anti-malarial treatment in rural Tanzania: implications for nationwide rollout of malaria rapid diagnostic tests. Malaria J 2012, 11(1):221. Available from: http://www.biomedcentral.com/content/pdf/1475-2875-11221.pdf.

21. Ifakara: Ifakara HDSS. 2013. Available from: http://www.indepth-network.org.

22. Mwageni, Masanja $H$, Juma $Z$, Momburi D, Mkilindi $Y$, Mbuya $C$, Kasale $H$, Reid G, De Savigny D: Socio-economic status and health inequalities in rural Tanzania: evidence from the Rufiji demographic surveillance system. Measurin Health Equity in Small Areas 2002:39-52.

23. Epidata: Available from: http://www.epidata.dk.

24. Stata: Available from: http://www.stata.com.

25. Font F, Alonso González M, Nathan R, Kimario J, Lwilla F, Ascaso C, et al: Diagnostic accuracy and case management of clinical malaria in the 
primary health services of a rural area in south-eastern Tanzania. Trop Med Int Health: TM \& IH 2001, 6(6):423-428. Available from: http:// onlinelibrary.wiley.com/doi/10.1046/j.1365-3156.2001.00727.x/pdf.

26. Winskill $P$, Rowland M, Mtove G, Malima RC, Kirby MJ: Malaria risk factors in north-east Tanzania. Malaria J 2011, 10(1):98. Available from: http://www. biomedcentral.com/content/pdf/1475-2875-10-98.pdf.

27. Okebe JU, Walther B, Bojang K, Drammeh S, Schellenberg D, Conway DJ, et al Prescribing practice for malaria following introduction of artemetherlumefantrine in an urban area with declining endemicity in West Africa. Malaria J 2010, 9:180. Available from: http://www.malariajournal.com/content/ pdf/1475-2875-9-180.pdf.

28. Reyburn H, Ruanda J, Mwerinde O, Drakeley C: The contribution of microscopy to targeting antimalarial treatment in a low transmission area of Tanzania. Malaria J 2006, 5:4. Available from: http://www. biomedcentral.com/content/pdf/1475-2875-5-4.pdf.

29. Chandler CIR, Jones C, Boniface G, Juma K, Reyburn H, Whitty CJM: Guidelines and mindlines: why do clinical staff over-diagnose malaria in Tanzania? A qualitative study. Malaria J 2008, 7:53. Available from: http:// www.malariajournal.com/content/pdf/1475-2875-7-53.pdf

30. Tamuno I: Prescription pattern of clinicians in private health facilities in Kano, Northwestern Nigeria. Arch Intern Med 2011:235-238.

31. Nshakira N, Kristensen M, Ssali F, Whyte SR: Appropriate treatment of malaria? Use of antimalarial drugs for children's fevers in district medical units, drug shops and homes in eastern Uganda. Trop Med Int Health: TM \& IH 2002, 7(4):309-316.

32. Font F, Alonso González M, Nathan R, Kimario J, Lwilla F, Ascaso C, et al: Diagnostic accuracy and case management of clinical malaria in the primary health services of a rural area in south-eastern Tanzania. Trop Med Int Health: TM \& IH 2001, 6(6):423-428.

33. Mannan A, Malik EM, Ali KM: Antimalarial prescribing and dispensing practices in health centres of Khartoum state, 2003-04. Eastern Mediterranean health journal = La revue de santé de la Méditerranée orientale = al-Majallah al-sihhiyah li-shara al-mutawassit 2009, 15(1):122-128. Available from: http://applications. emro.who.int/dsaf/dsa971.pdf\#page=122.

34. Bashrahil K, Bingouth aS, Baruzaig aS: Antimalarial drugs: availability and mode of prescribing in Mukalla, Yemen. Eastern Mediterranean health journal $=$ La revue de santé de la Méditerranée orientale = al-Majallah al-sihhiyah li-sharq al-mutawassit 2010, 16(2):146-150. Available from: http:// applications.emro.who.int/emhj/N16/02/16_2_2010_0146_0150.pdf.

35. Oshikoya KA: Antimalarial prescriptions for children presenting with uncomplicated malaria to a teaching hospital in Nigeria after the change of national guidelines for malaria treatment. J Med Sci 2007, 2(1):49-53.

36. Dodoo ANO, Fogg C, Asiimwe A, Nartey ET, Kodua A, Tenkorang O, et al: Pattern of drug utilization for treatment of uncomplicated malaria in urban Ghana following national treatment policy change to artemisinin-combination therapy. Malaria J 2009, 8:2. Available from: http://www.biomendcentral.com/content/pdf/1475-2875-8-2.pdf.

37. Shamshy K, Begum IM, Perumal P: Drug utilization of antimicrobial drug in pediatrics population in a tertiary care hospital in Erode, Tamilnadu India. Int J PharmTech Res 2011, 3(3):1530-1536.

38. Watsierah $\mathrm{C}$, Jura WGZO, Oyugi $\mathrm{H}$, Abong'o B, Ouma C: Factors determining anti-malarial drug use in a peri-urban population from malaria holoendemic region of western Kenya. Malaria J 2010, 9(1):295.

doi:10.1186/1471-2458-13-1097

Cite this article as: Njozi et al:: Predictors of antibiotics co-prescription with antimalarials for patients presenting with fever in rural Tanzania. BMC Public Health 2013 13:1097.

\section{Submit your next manuscript to BioMed Central and take full advantage of:}

- Convenient online submission

- Thorough peer review

- No space constraints or color figure charges

- Immediate publication on acceptance

- Inclusion in PubMed, CAS, Scopus and Google Scholar

- Research which is freely available for redistribution

Submit your manuscript at www.biomedcentral.com/submit
C) Biomed Central 